\title{
La fotografía turística de interacción icónica: identidad de representación simbólica de imagen personal en el destino
}

\section{Tourist photography of iconic interaction: identity of symbolic representation of personal image in the destination}

Antonia Pérez-García (iD, Escuela Universitaria de Turismo, Universidade da Coruña antonia.perezg@udc.es

\section{RESUMEN}

Con la aparición de las redes sociales, el uso generalizado del Smartphone, la presión de la inmediatez, exaltación y necesidad de representación y significación simbólica ante los otros, se ha generalizado la práctica de un tipo de fotografía turística; aquella realizada tomando la imagen del turista-protagonista interactuando con un icono turístico, relevante por su representación simbólica, formando una imagen de proyección personal en el destino. Se ha denominado a este formato: «fotografía turística de interacción icónica». El estudio se ha centrado en los iconos más buscados de Europa con el objetivo de analizar los motivos y funciones que rodean esta práctica simbólico-fotográfica. Se ha aplicado una metodología mixta cualitativa-cuantitativa a través de las técnicas de investigación del análisis de contenido icónico y la encuesta. Los resultados han contribuido a comprender, desde una perspectiva sociológica, este comportamiento de representación simbólica de imagen personal en el destino, mostrándose una tendencia generalizada en la realización de este tipo de fotografía de interacción con ciertos iconos turísticos representativos, independientemente de variables como la edad o el sexo. La necesidad de informar y proyectar una narrativa vacacional simbólica hacia el entorno social cercano subyace tras este tipo de comportamiento fotográfico.

Palabras clave: Turismo; interacción; icono; fotografía; representación simbólica.

\section{ABSTRACT}

The emergence of social networks, the widespread use of the smartphone, the pressure of immediacy, exaltation and the need to be represented and have symbolic significance in the eyes of others has given rise to a kind of tourist photography that is based on taking images of the tourist-protagonist interacting with a tourist icon which is famous for its symbolic representation, creating an image with a personal projection in the destination. This format has been called «Iconic Interaction Tourist Photography». This study focuses on the most popular 
icons in Europe in order to analyse the intentions and purposes that underlie this symbolic-picture practice. A qualitative-quantitative mixed methodology has been applied through icon content analysis and survey techniques. The results have contributed to enhancing our understanding of this behaviour in the symbolic representation of personal image in the destination from a sociological perspective, showing an overall trend towards this kind of interaction photography with certain representative tourist icons regardless of factors such as age or gender. The need to report a narrative symbolic holiday telling to the close social circle lies behind this photographic behaviour pattern.

Keywords: Tourism; interaction; icon; photography; symbolic representation.

\section{INTRODUCCIÓN}

La fotografía puede adoptar diferentes interpretaciones, lecturas o análisis, dependiendo del contexto en el que se realice, de la intencionalidad del propio autor o por parte de las personas que realicen la interpretación. La fotografía turística, desde sus primeros tiempos en blanco y negro, ha constituido un elemento imprescindible vinculado al disfrute del ocio o la práctica turística, dado que permite rememorar la experiencia vivida y ejercer la función de demostración simbólica y distinción ante los demás.

Guash (2013) muestra la fotografía como una herramienta que permite guardar y coleccionar recuerdos del pasado, permite construir una historia. Esta historia puede ser edificada sobre un imaginario real o incluso fantasioso (Hiernaux, 2012). La fotografía ofrece un reflejo de la realidad sin ambigüedades (Barthes, 1989), donde lo importante es la función de interpretación porque ésta viene dada a través de la impresión fotográfica (Machado, 2010).

Por otro lado, la fotografía puede conformarse en una representación de la identidad simbólica de un objeto como lo puede ser un destino, contagiar emociones de forma que despierte el deseo de visitar un lugar e incluso despertar el deseo de emular comportamientos o experiencias (Hart, 2016; Azevedo, 2017). Es una herramienta de comunicación personal donde lo visitado se transforma en discurso y la fotografía es la apropiación y resignificación simbólica (Raurich, 2009).

En los últimos tiempos ha surgido la proliferación de un tipo de fotografía realizada de una forma concreta, desde un determinado lugar, en la cual el turista-protagonista y el icono turístico interaccionan formando un conjunto de redefinición simbólica. Imágenes que se repiten incansablemente, como fotocopias de la original. Es posible que la captura de una de estas fotografías obligue al turista-protagonista a esperar una larga cola, buscar una calle o punto específico o rodearse de los elementos necesarios para su puesta en escena. Pero todo este esfuerzo se convierte en una nimiedad frente al objetivo final de obtener la imagen deseada, pues el resultado y la publicación compartida de la misma le reportará una representación simbólica de identidad social, de imagen personal de destino, de distinción ante los otros.

Este tipo de fotografía no se encuadraría en ningún género específico. Si se atiende a su función, el objetivo es el referente, es decir, el objeto con el que el turista-protagonista 
interactúa o se relaciona. Su realización requiere la búsqueda de los ingredientes necesarios para su perfecto simbolismo representativo, y en todos ellos se realiza una acción de relación con el icono turístico por parte del turista-protagonista. El turista-protagonista pasa a ser un sujeto activo en la imagen fotográfica.

A través de este tipo de fotografía turística de interacción, realizada con el uso generalizado del Smartphone, se informa sobre las experiencias turísticas vividas, lo que permite proyectar simbología e identidad, de imagen personal en el destino y distinción de forma inmediata. De ahí que las redes sociales, dirá Luna (2015), sean las herramientas perfectas para proyectar el consumo simbólico de las vacaciones ante los otros, además de permitir reforzar la identidad.

Este modelo de fotografía de interacción abarca diferentes tipos de elementos: animados, como interactuar con animales-iconos o personajes-iconos, o inanimados, como interaccionar con monumentos-iconos, esculturas-iconos $u$ otra serie de objetos iconos del destino. Uno de los ejemplos más célebres es la imagen del turista-protagonista sujetando o empujando la Torre de Pisa (Italia).

El presente estudio se ha centrado en los iconos turísticos inanimados más relevantes y buscados de Europa (monumentos, esculturas y otros objetos simbólicos) con el objetivo de analizar los motivos y funciones que definen este tipo de fotografía y de comportamiento turístico simbólico-fotográfico. Como se podrá atender en el apartado de discusión y conclusiones, los resultados contribuyen a comprender mejor, desde una perspectiva sociológica, esta práctica fotográfica por parte del turista, de la búsqueda de proyección de una representación simbólica de imagen personal en el destino.

Se advierte que, al carecer de una denominación específica de este tipo de fotografía turística descrita, ha sido designada por la autora del presente estudio como: «fotografía turística de interacción icónica».

\section{MARCO TEÓRICO}

No se han hallado estudios sobre este tipo concreto de fotografía turística de interacción icónica, por lo que la revisión de la bibliografía se ha centrado en el papel de la fotografía en general y la fotografía personal turística del destino en particular, la necesidad y los motivos de compartirla en las redes sociales, así como la explicación sociológica de la función de interacción simbólica con un icono turístico en el destino.

\subsection{Importancia de la fotografía turística}

El viajero del siglo XIX, apoyado por las expediciones gubernamentales, se convertiría en el primer sujeto en realizar fotografía turística de tipo documental, siendo éstas las primeras de las cuales se tienen constancia (Vega, 2011). Y será con la extensión del boom turístico, en la segunda mitad del siglo XX, cuando se extienda la fotografía turística de algunos destinos o monumentos por todo el mundo (Pérez, 2015). Estas imágenes fotográficas con el paso del tiempo han conseguido que ciertos destinos y objetos turísticos destacasen por encima de 
otros, pues la acción reiterativa de la realización de este tipo de fotografía vendría a reforzar la representación icónica-simbólica de los lugares y objetos turísticos más buscados. Afirman Stepchenkova y Zhan (2012) que este tipo de imágenes personales se han popularizado más que las creadas y proyectadas a través del marketing para la industria turística, lo que ha venido a reforzar exponencialmente la realización de las mismas.

López de Letona (s.f.) concluye que el turismo masificado se centra más en la búsqueda de imágenes fotográficas que en el disfrute de la experiencia de ocio. No se viaja para ver, sino para realizar fotografías de los iconos turísticos masificados, pues el individuo es un turista alienado y pasivo en este sentido. La imagen fotográfica se configura como uno de los elementos o iconos fundamentales de la práctica turística (Luque et al., 2006 y Donaire y Galí, 2011, Hernández y Poggio, 2016). Es impensable viajar sin portar una cámara fotográfica, porque será ésta la que permita mostrar la prueba irrefutable del viaje realizado (Sontag, 2005), la cámara se convierte en una posesión simbólica, en una herramienta de control que ejerce, al mismo tiempo, una dependencia del turista-usuario (Barrios, 2010). Es uno de los elementos simbólicos que adquiere el turista y que le permite situarlo en un contexto de experiencia turística, distinto al de la vida cotidiana (Jafari, 2007).

Actualmente existe un comportamiento compulsivo a fotografiar experiencias, éstas se convierten en una forma concreta de mirar, por lo que el viaje se llega a convertir en el pretexto ideal para realizar fotografías (Sontag, 2010). Pero la fotografía también ha contribuido a construir y reforzar imágenes estereotipadas de ciertos lugares, supliendo la autenticidad de éstas por simples escenas burlescas y banales (Gómez, 2009).

Se puede decir que existe una expresa y contundente retroalimentación simbiótica entre fotografía y turismo. Fuentes (2014) argumenta que existe una alianza entre turismo y fotografía que se ha traducido en una socialización normativizada en los viajes. La fotografía ha contribuido a popularizar destinos, monumentos y otro tipo de objetos turísticos. A su vez la práctica turística ha reforzado la difusión y promoción de la fotografía, tanto de tipo comercial como personal. Daríes-Román, Cristóbal-Fransi y Martín-Fuertes (2014) inciden en que la información vertida en las redes sociales ejerce la función de guiar las decisiones de potenciales visitantes a un destino, además de generar reputación del destino (Caro, Luque y Zayas, 2015). En torno a esta simbiosis, Garrod (2009) expone que existe cierta circularidad de la relación entre las imágenes que utiliza la industria del turismo y lo que recibe el turista, puesto que este, en ocasiones, reproduce las mismas fotografías turísticas proyectadas por dicha industria, cerrando un círculo de representación auto-reforzada de imágenes de un destino.

\subsection{La necesidad de compartir en redes sociales}

Autores, como González Fernández-Villavicencio (2012), reflexiona sobre el cambio radical y vertiginoso que ha sufrido la forma de acceder y usar la información, tanto en los sitios webs como en las redes sociales. Las redes sociales, en general, tienen una motivación lúdica, social, informativa y psicológico-afectiva (Ramos y Del Pino, 2014). Han transformado la realidad social, porque manipulan la verdad, por lo que los propios sujetos son responsables de la realidad que han creado (Reig y Vilcher, 2013). 
El uso generalizado del espacio virtual ha traído consigo consecuencias de diversa índole. Lara (2011) afirma que en el mundo virtual el individuo puede crear múltiples identidades públicas virtuales, que en el caso de los más jóvenes refuerza la identidad de pertenencia al grupo (Ferré y Bernal, 2014); les permite compartir experiencias y obtener reconocimiento de su actividad ante los otros (Colás, González y De Pablos, 2013), por lo que el usuario necesita ser consciente de este fenómeno, por el alcance de las consecuencias de sus acciones digitales.

En el estudio de Sheungting y McKercher (2015) se establece que, actualmente, la fotografía publicada en las redes sociales facilita la comparación social, de forma que se está produciendo una redefinición de la mirada turística. Parece que actualmente el viaje turístico necesita de la demostración pública en las redes sociales, de compartir experiencias, gustos y cierto fingimiento escenográfico por parte de diferentes individuos pertenecientes a distintos grupos sociales (Menezes y Gândara, 2015). Es una forma diferente de hacer visible o pública una parte de la vida de aquellos que durante un periodo de tiempo practican el ocio turístico. Esto ha hecho que sea el propio turista un sujeto activo en la construcción de la imagen de un destino (Donaire y Galí, 2011).

En esa misma línea, Gallego (2015) afirma que se necesita el refuerzo del ajeno a través del «like» en la fotografía compartida, de forma que la misma sigue todo un proceso ritual. Gallego sigue argumentando que se han impuesto unas pautas de comportamiento con tendencia al narcisismo, al auto espectáculo, al exhibicionismo, a la necesidad de compartir el reconocimiento de la imagen fotográfica. Se comparte de forma inmediata, eliminando la importancia de la selección premeditada. Bajo este mismo contexto, afirma Canavan (2017) que actualmente existe un aumento del narcisismo asociado al turismo, turismo consumista, egoísta, exhibicionista y hedonista en el cual, tanto los factores sociales como tecnológicos, lo han potenciado. En el tipo de fotografía personal y cotidiana, la inmediatez y la producción instantánea perecedera tienen su explicación en relación a la ubicuidad, conectividad y movilidad de los sujetos, correlacionadas con el uso de los dispositivos inteligentes (Van Dijck, 2008; Van House, 2011).

Las imágenes fotográficas son compartidas, comentadas y publicadas de forma inmediata (Zheng y Gretzel, 2010). La inmediatez en el hecho de compartir en redes sociales parece estar más difundida entre los jóvenes, los cuales se hallan inmersos en una presión social propia de una generación consumidora, permanentemente conectadas e informada (Ferré y Bernal, 2014). El auge de redes sociales como Facebook o Twitter, actualmente más relegadas por Instagram, Printest o Snapchat, han potenciado la construcción y proyección de la identidad pública de los individuos. Según un estudio realizado por Prades y Carbonell (2016), los jóvenes se han pasado de Facebook a Instagram porque, además de ofrecerles intimidad, el objeto principal de esta segunda plataforma se centra en la fotografía. Al igual que la plataforma de Snapchat, también muy utilizada por los jóvenes, pero con un contenido más efímero. En el estudio de Lo, et al. (2011), centrado en el uso de fotografías turísticas en línea en Hong Kong, estos autores concluyen que tienden a ser los más jóvenes los usuarios de este tipo de fotografía compartida, principalmente a través de redes sociales, blogs personales y mensajería instantánea. 


\subsection{Análisis sociológico de la fotografía turística de interacción icónica}

Bericat (2012) hace referencia al hecho de que la sociología no se ha preocupado en demasía de la cultura visual o de analizar las imágenes para obtener conocimiento social, siendo la fotografía el material empírico que mejor posibilita la observación y explicación sociológica de la relación existente entre el objeto y su representación, debido a que contiene conocimiento sobre la realidad social. La fotografía es la demostración concluyente del relato vacacional y de la proyección de estatus social (Sidun, 2008), es una importante fuente documental histórica de análisis de la imagen turística (García del Toro, 2016), permite nuevas miradas y perspectivas de comprensión de la experiencia de ocio en el espacio-urbano turístico (Manosso y Gândara, 2016). Además, este tipo de fotografía refleja las percepciones de los turistas sobre un destino (Stepchenkova y Zhan, 2012); son fotografías moldeadas por la construcción cultural del lugar, además de otro tipo de factores sociales y visuales, por lo que el turista se convierte en un productor cultural activo (Stylianou-Lambert, 2012), cuestiones estas también objeto de análisis sociológico.

Cuando se realiza una fotografía turística de interacción icónica se proyecta sobre ella una intencionalidad, tanto por parte del fotógrafo como del sujeto protagonista de la misma, por lo que se hace necesario analizar las motivaciones reales que la crean. A esto hay que sumarle el hecho de que las imágenes fotográficas turísticas compartidas condicionan el comportamiento de futuros turistas que desean reproducirla al visitar el destino. Este análisis es importante hacerlo desde la perspectiva sociológica, puesto que permite comprender mejor las motivaciones y funciones de esta forma concreta de comportamiento turístico. La revisión de algunos paradigmas teóricos clásicos, como los siguientes, facilitan el análisis:

El interaccionismo simbólico o enfoque dramatúrgico de Goffman (1971) permite explicar cómo los turistas realizan el ocio o viaje turístico como si se tratase de una representación teatral simbólica ante los demás. Por lo tanto, también se podría explicar el fenómeno de la necesidad de interaccionar simbólicamente con un icono turístico para representar un papel social ante los demás. El turista finge una acción de interacción con el icono fotografiado como si fuese una obra de teatro, de apariencia ante los grupos sociales de interés. González Damián (2010) resalta que este paradigma permite analizar la acción conjunta en el espacio turístico, comprender el uso que hacen las personas de los significados y símbolos de su actuación.

Otro de los paradigmas explicativos sería la etnometodología de Garfinkel, corriente surgida en los años sesenta; aunque González Damián (2010) advierte de la escasez de estudios desde esta teoría aplicados al turismo. No obstante, se podrían analizar las prácticas de interacción entre sujetos que dan sentido a la construcción del mundo social. En este caso se podría abordar un análisis de la interacción turista-icono, es decir, de comportamientos ejecutados en la construcción de la identidad e imagen simbólica personal en el destino, transmitida a través de la fotografía.

Álvarez Sousa (2009) cree que la teoría de la clase ociosa de Veblen, ayuda a interpretar mejor el tipo de comportamiento de apariencia ante los demás, pues existe una necesidad de valoración social. Al revisar dicha teoría de Veblen (2010), éste incide en la idea del consumo ostentoso de la apariencia social, puesto que ésta aporta al individuo prestigio y status, a 
través de determinados comportamientos de práctica de actividades ociosas y de diversión que le aporten reputación. Por lo tanto, el viaje turístico, y por ende la vida ociosa y la documentación fotográfica de ciertos iconos, son esenciales, es un proceso de demostración social.

Bourdieu (2003) habla del consumo de prácticas, no necesarias para la vida cotidiana, sino prácticas realizadas para obtener distinción ante los demás, ostentación de una clase social, por lo tanto, el turista imitaría este comportamiento de realización de fotografía turística de interacción icónica como un elemento de distinción y referente identitario para otros turistas. El turista protagonista escoge la imagen de un contexto o entorno concreto por su alto contenido simbólico. Dirá Fuentes (2014) que el turista se siente protagonista realizando fotografías de los iconos que son fotografiados por otros sujetos, porque necesita «el reconocimiento afianzado" (p.22) que menciona Bourdieu, lo representado se repite, "el registro se limita a crear normas de apariencia y la revolución visual confirma solamente otros hábitos de visión» (p.24).

Esta práctica fotográfica también se puede analizar desde el paradigma o teoría sociológica del conflicto, sería un análisis crítico sobre la banalización de la cultura, pérdida de respeto hacia la identidad del icono turístico fotografiado, así como su consiguiente pérdida de autenticidad (Gómez Lozano, 2009), tal y como se mencionó anteriormente. Un ejemplo de ello y que generó un intenso debate en 2017 fue la publicación de fotografías turísticas en tono burlesco en redes sociales, algunas de ellas de interacción icónica, con los monumentos del Holocausto en Auschwitz en Alemania (News.Mundo, 2017).

\section{METODOLOGÍA}

Objetivo general: Conceptualizar y analizar la fotografía de interacción icónica. Objetivos específicos: Determinar los iconos más relevantes y buscados en Europa de fotografía turística de interacción icónica, centrado en los iconos turísticos inanimados (monumentos, esculturas y objetos simbólicos). Conocer los motivos y funciones que rodean la práctica de este comportamiento simbólico-fotográfico.

Se aplica un enfoque metodológico de investigación exploratoria de tipo mixto (cualitativo-cuantitativo), realizando una revisión previa de búsqueda de fotografías de interacción icónica a través de Internet y redes sociales (principalmente en Facebook e Instagram). La selección de dichas fotografías se realiza por conveniencia, teniendo en cuenta que son algunos de los iconos turísticos más populares y visitados de Europa, según consta en las páginas oficiales de turismo de estas ciudades, por lo que también son los más fotografiados con algún tipo de interacción. El análisis de contenido de las fotografías seleccionadas se realiza atendiendo a las siguientes variables: tipo de imagen, país/ciudad, tipo de icono, tipo de interacción y resignificación de la imagen.

En cuanto al diseño y aplicación de una encuesta, ésta consta de 14 ítems que incluye variables sociodemográficas, y variables específicas sobre el objeto de estudio, la cual es diseñada en google drive. Para la validación de la encuesta se realiza un pretest a un total de 15 sujetos, lo que permite corregir posibles errores y sesgos de diseño. La investigación se realiza de enero a junio de 2019 y se recogieron un total de 445 encuestas. 
En una primera fase se calcula la muestra ( $n$ ), la cual se circunscribe a la provincia de $A$ Coruña con una población de 1.119 .351 habitantes $(\mathrm{N})$, según datos del IGE ${ }^{1}$. El cálculo de la misma, con un 5,2\% de error muestral (e), un 95\% de intervalo de confianza ( $p$ ) y un 1,96 de nivel de confianza, arroja la cifra de 355 como tamaño de la muestra (n) necesaria, número que se halla dentro de nuestra muestra final de observación (357 encuestas), una vez eliminados los individuos no válidos de las 445 encuestas inicialmente recogidas, por no cumplir las premisas de partida: realizar fotografía de interacción icónica y residir en A Coruña provincia. Los datos estadísticos han sido tratados a través del programa SPSS, versión 25.

En la fase de muestreo, en el momento de diseñar la metodología de investigación se observa que el uso de redes sociales y otros métodos online permitirían acceder a sujetos ocultos que cumplen la principal premisa de partida: sujetos que hayan realizado fotografía de interacción icónica al viajar por Europa. La revisión de la literatura y estudios basados en este tipo de muestreo la señalan como una estrategia básicamente diseñada para detectar casos en donde el tamaño de la población universo es desconocida (Heckathorn 1997, 2002; Verd y Martí, 1999; Baltar y Gorjup, 2012), y en este caso se desconoce la población que realiza este tipo de fotografía de interacción icónica. En concreto el muestreo online o la tradicional bola de nieve de tipo lineal, discriminatorio o no discriminatorio exponencial es una técnica que permite acceder a individuos de baja incidencia o de difícil acceso (población oculta) a través de redes sociales u otros métodos online (Brickman-Bhutta, 2009; Silenzio et al., 2009; González y Sosa, 2018).

Por lo tanto, la fase de envío se diseña a través de redes sociales (Facebook e Instagram), correo electrónico y WhatsApp de la Red Personal de Contactos dentro de la provincia de A Coruña (Galicia-España). Siguiendo este modelo y pensando en el efecto exponencial discriminatorio de este tipo de muestreo, la aplicación se deja abierta durante 45 días, ello ha permitido localizar a un total de 357 sujetos válidos $(80,2 \%)$ que cumplen la premisa principal de partida, pertenecientes a 20 subgrupos identificados dentro de la provincia de A Coruña. Por lo tanto, quedan eliminadas 88 encuestas $(19,8 \%)$ del total de las 445 recogidas inicialmente por no cumplir los criterios de selección previa, anteriormente mencionados.

Hipótesis de partida: Los turistas-protagonistas más jóvenes son los que habitualmente realizan este tipo de fotografía, siendo por igual hombres y mujeres (H.1.). Los turistas-protagonistas más jóvenes son los que comparten habitualmente de forma más inmediata este tipo de fotografía (H.2.). Se repiten mayoritariamente los iconos turísticos más conocidos en Europa (H.3). El motivo principal de la realización de este tipo de fotografía es porque son fotografías típicas (H.4). El motivo principal de compartir este tipo de fotografía es para informar a su círculo social y mostrar públicamente su actividad turística (H.5).

1. Instituto Gallego de Estadística (datos a 1 de enero de 2018) 


\section{RESULTADOS Y DISCUSIÓN}

Realizada una revisión previa en Internet y redes sociales (Facebook e Instagram), tal y como se detalla en la metodología, se destacan los siguientes ejemplos de fotografías de interacción icónica más populares en Europa (marcado en sombreado color gris):

Tabla 1. Imágenes fotográficas de interacción icónica en Europa

\begin{tabular}{|c|c|c|c|}
\hline Icono & Interacción (Acción) & Ciudad & País \\
\hline Torre inclinada o pendiente & $\begin{array}{l}\text { Sujetando } \\
\text { Empujando } \\
\text { Saltando } \\
\text { Abrazando } \\
\text { Tomando un helado en forma de cucurucho } \\
\text { Acciones de simbología fálica } \\
\end{array}$ & Pisa & Italia \\
\hline Bocca della Veritá & Meter la mano en la boca & Roma & Italia \\
\hline Torre Eiffel & $\begin{array}{l}\text { Cogiendo la torre por el vértice } \\
\text { Cogiendo la torre completa } \\
\text { Sosteniendo la torre con las manos }\end{array}$ & París & Francia \\
\hline Museo Louvre & $\begin{array}{l}\text { Cogiendo el vértice del prisma } \\
\text { Apoyando la mano en el vértice } \\
\text { Sujetando la pirámide }\end{array}$ & París & Francia \\
\hline $\begin{array}{l}\text { Paso de cebra de Abbey } \\
\text { Road (portada de los } \\
\text { Beatles) }\end{array}$ & Cruzando el paso & Londres & Inglaterra \\
\hline Cabina roja de teléfono & Haciendo una llamada & Londres & Inglaterra \\
\hline $\begin{array}{l}\text { Grafiti del beso entre } \\
\text { Honecker y Leónidas } \\
\text { Breznev en el Muro }\end{array}$ & Besándose delante del grafiti & Berlín & Alemania \\
\hline Escultura del Ágora & Imitando la misma pose de la escultura & Atenas & Grecia \\
\hline Estadio de Olimpia & En posición de iniciar una carrera & Olimpia & Grecia \\
\hline Coliseum & Sujetando con la mano por la base & Roma & Italia \\
\hline Catedral & Sujetando la catedral por la base & Milán & Italia \\
\hline Palacio de la Patria & Sujetando el Palacio por la base & Roma & Italia \\
\hline Góndolas & Remando la góndola & Venecia & Italia \\
\hline David de Miguel Ángel & Imitando la misma pose de la escultura & Florencia & Italia \\
\hline Puente Rialto & Cruzando el puente & Venecia & Italia \\
\hline Estatua del Jabalí & Tocando, abrazando el jabalí & Florencia & Italia \\
\hline Menhires & Abrazando el menhir & Bretaña & Francia \\
\hline Museo de Toulouse Lautrec & Sujetando el edificio con la mano & Albi & Francia \\
\hline Parque temático Furoscope & Sujetando la bola gigante & Poitiers & Francia \\
\hline $\begin{array}{l}\text { Réplica de la estatua de la } \\
\text { Libertad }\end{array}$ & Dándole la mano o sujetando la estatua & Colmar & Francia \\
\hline Oso del Guggenheim & Abrazando el oso & Bilbao & España \\
\hline
\end{tabular}




\begin{tabular}{|l|l|l|l|}
\hline Sagrada Familia & Sujetando o cogiendo la catedral & Barcelona & España \\
\hline Torre de Hércules & $\begin{array}{l}\text { Sujetando la Torre por la base } \\
\text { Cogiéndola la Torre por la parte superior }\end{array}$ & A Coruña & España \\
\hline Rosa de los vientos & Imitando en el suelo la rosa de los vientos & A Coruña & España \\
\hline Piedra de cuarcita & Sujetando la piedra & $\begin{array}{l}\text { Monsanto } \\
\text { Cáceres }\end{array}$ & España \\
\hline Calle «Beso de la esquina» & Besándose en la esquina de la calle & Rota Cádiz & España \\
\hline Balneario Caldea & Sujetando o cogiendo la cúpula exterior & $\begin{array}{l}\text { Andorra la } \\
\text { Vella }\end{array}$ & Andorra \\
\hline Figuras de los nomos & Imitando a los gnomos & & Noruega \\
\hline Escultura de Magallanes & Dando la mano a la escultura & Azores & Portugal \\
\hline Tranvía & Sujetando el tranvía & Lisboa & Portugal \\
\hline Escultura de Pessoa & $\begin{array}{l}\text { Sentándose al lado e interactuando en } \\
\text { conversación }\end{array}$ & Lisboa & Portugal \\
\hline Bancos de sentarse & En los jardines de San Antón & Attard & Malta \\
\hline
\end{tabular}

En sombreado gris se muestran los iconos y la interacción hallada en imágenes publicadas en redes sociales e Internet. Sin sombreado los iconos y su interacción, información extraída de las encuestas, siendo descartados todas las referencias que no tuviesen que ver con Europa. Fuente: elaboración propia

Torre pendiente di Pisa: Construida en 1173 y ubicada en la ciudad de Pisa, es la torre campanario de la catedral de Pisa, situada en la plaza del Duomo. Es una de las fotos turísticas de interacción icónica más repetida del mundo. Con todo tipo de interacción: sujetando, empujando, saltando, abrazando, tomando la torre como un helado, acciones relacionadas con la simbología fálica, etc.

Figura 1. Fotomontaje de la Torre de Pisa

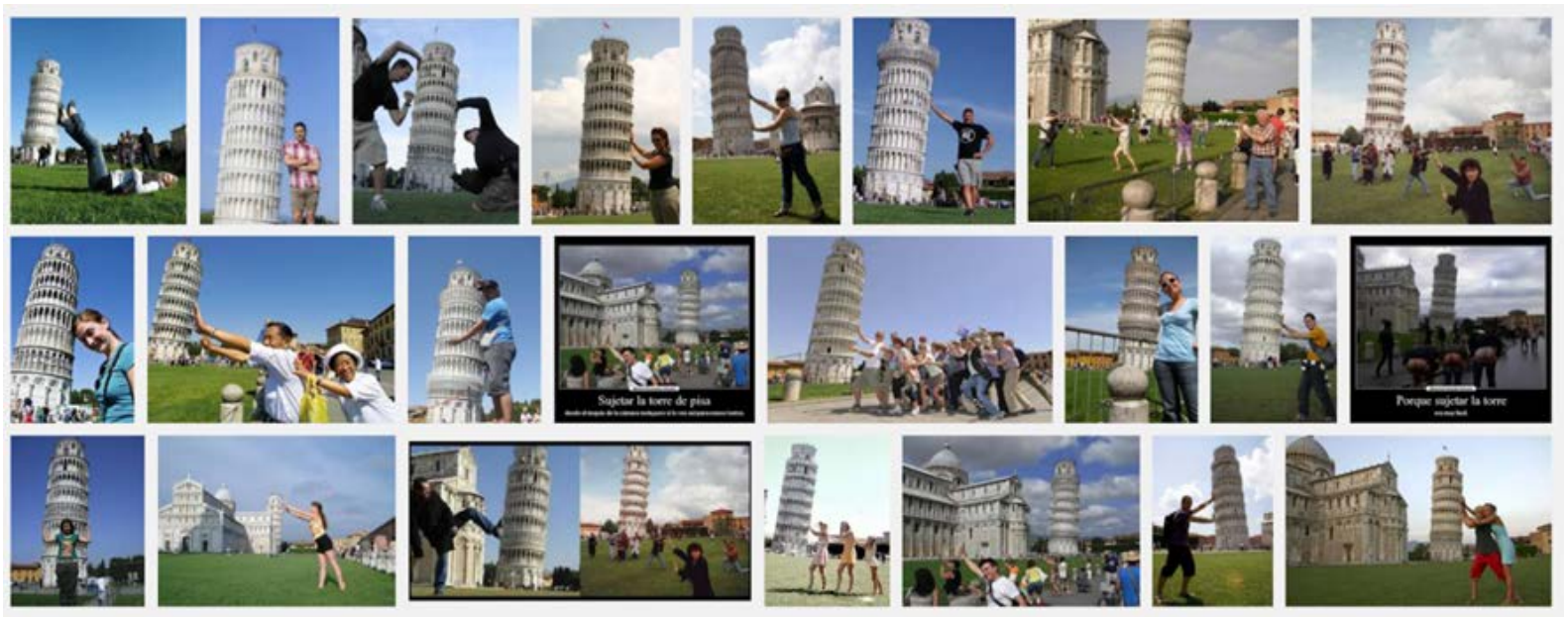

Fuente: https://www.recreoviral.com/lugares/fotos-divertidas-torre-pisa/

Bocca della Veritá: Esta escultura se hallaba en la Plaza de la Bocca della Veritá (Roma) hasta que en 1632 fue trasladada a la Iglesia de Santa María in Cosmedin, donde se puede ver 
actualmente. Existe en torno a ella una leyenda, de forma que los visitantes que han mentido, al introducir la mano por la boca, serán mordidos. Una de las escenas más emblemáticas de la película «Vacaciones en Roma» (1953) protagonizada por Gregory Peck y Audrey Hepburn y dirigida por William Wyler, es reflejo de esta concreta interacción icónica.

Figura 2. Boca della Veritá (Roma)
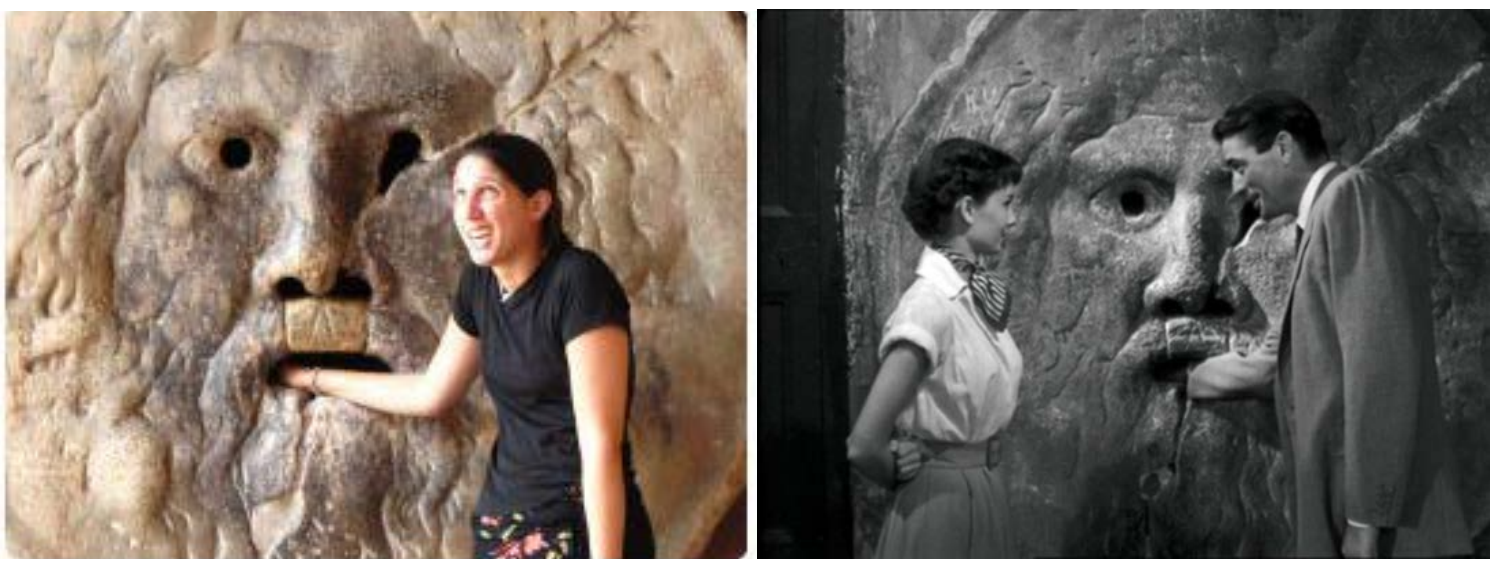

Fuentes: https://www.informagiovani-italia.com/roma es.htm; https://civitavecchia.portmobility.it/es/ la-boca-de-la-verdad

Torre Eiffel: La Torre Eiffel se construyó entre 1887 y 1889, en conmemoración del centenario de la Revolución Francesa, y desde que se inauguró en 1889 se convirtió en el icono por excelencia de la capital francesa. Es el cuarto icono turístico más visitado del mundo (El Confidencial, 31/03/2019), y se fotografía desde todos los ángulos posibles, además de las fotografías turísticas de interacción icónica.

Figura 3. Torre Eiffel (París)

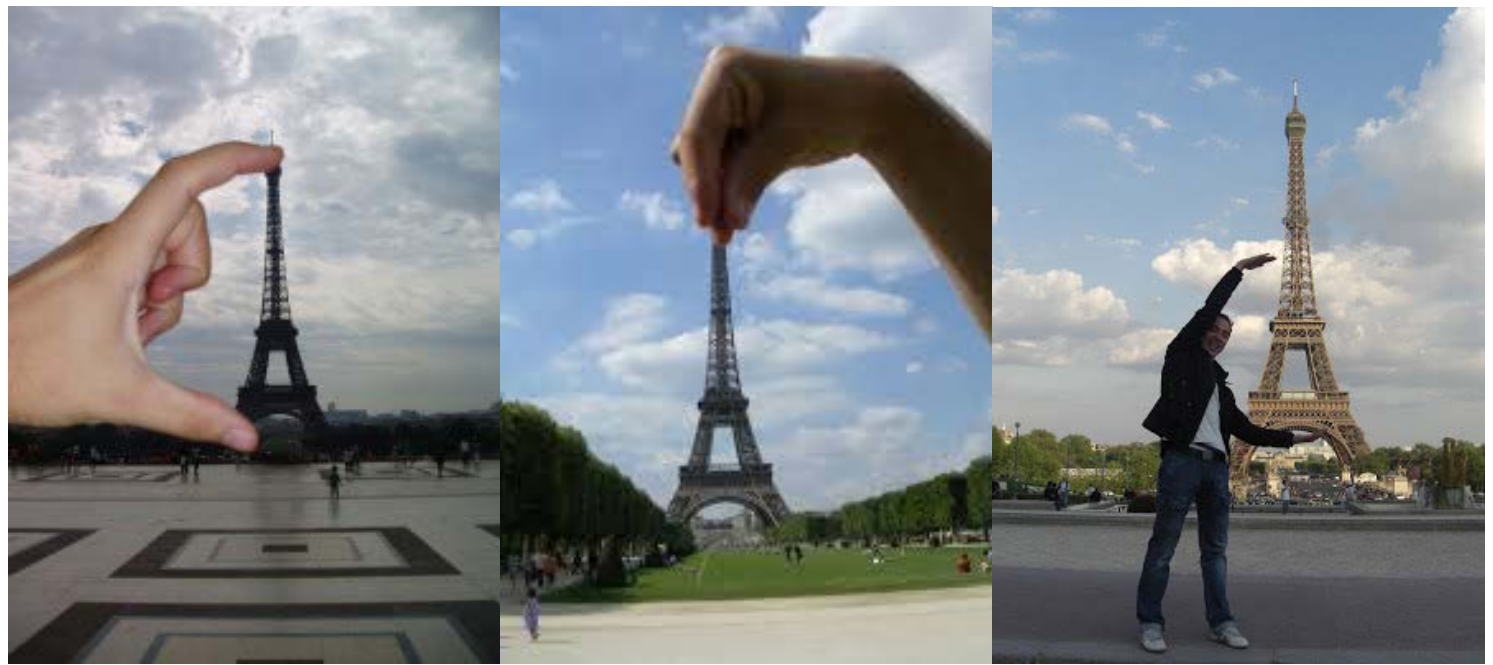

Fuente: http://esmateria.com/2012/09/21/nobel-alternativo-por-encoger-la-torre-eiffel/;https://xgfkocd.files. wordpress.com/2009/11/curiosas89g.jpg; http://cartonianosporelmundo.blogspot.com/2010/01/4-dias-enparis.html 
Prisma del Museo Louvre: En 1983, Leoh Ming Pei fue designado para acondicionar una nueva entrada para recibir al público y organizar el interior del museo Louvre. Ming Pei diseñó la pirámide de cristal con acceso que se abrió en 1989 (año del bicentenario de la Revolución Francesa) (Paris CityVision, 2019). Aunque fue muy criticada originariamente, hoy la pirámide cuenta con el apoyo tanto de los visitantes como de los parisinos. Ésta se integró al palacio e incluso se convirtió en una atracción turística en sí. No es raro ver a los transeúntes haciéndose una foto delante de la pirámide o intentando coger a ésta. Además de ser una entrada al patio del palacio, la gran pirámide se convirtió en el símbolo del Louvre.

Figura 4. Pirámide del Museo Louvre (París)

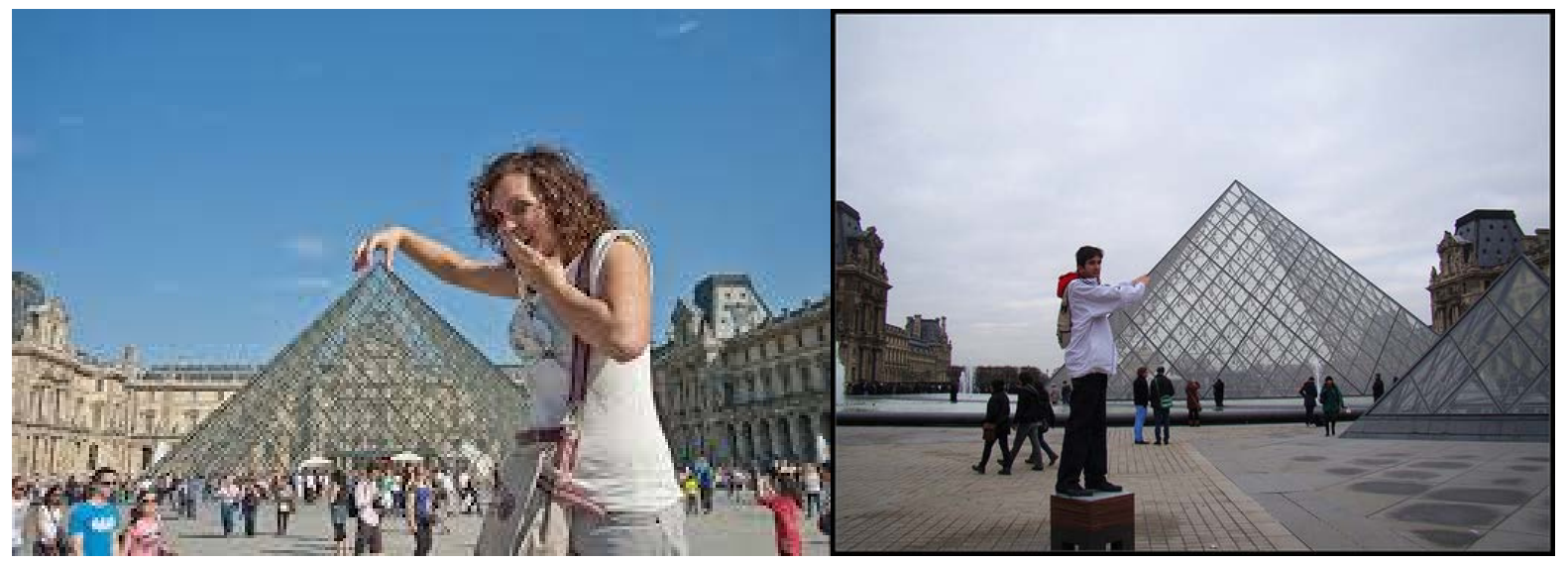

Fuentes: https://www.fotonazos.es/2011/06/visitar-paris-dia-1/; https://www.laproximaparada.com/2011/02/ dia-4-paris-2-enero/

Paso peatonal de Abbey Road: Abbey Road (1969) fue el título del último disco de los Beatles, y se ha convertido en una imagen simbólica de por sí. En ella se ve a los cuatro miembros cruzando el paso de cebra y alejándose del estudio y sello discográfico de ese último disco. Se ha convertido en el paso de cebra más famoso del mundo, por lo que se ha configurado como uno de los iconos turísticos más emblemáticos de la visita a Londres, no siendo posible cuantificar cuántos turistas realizan la fotografía en este punto concreto. Algunos turistas incluso reproducen todos los elementos iconográficos de la célebre portada del disco. Su imagen icónica ha sido reproducida en diferentes series de televisión como una iconografía simbólica internacional, en el ejemplo vemos la imagen reproducida en la serie de animación de los Simpson. 
Figura 5. Paso de cebra de Abbey Road (Londres)

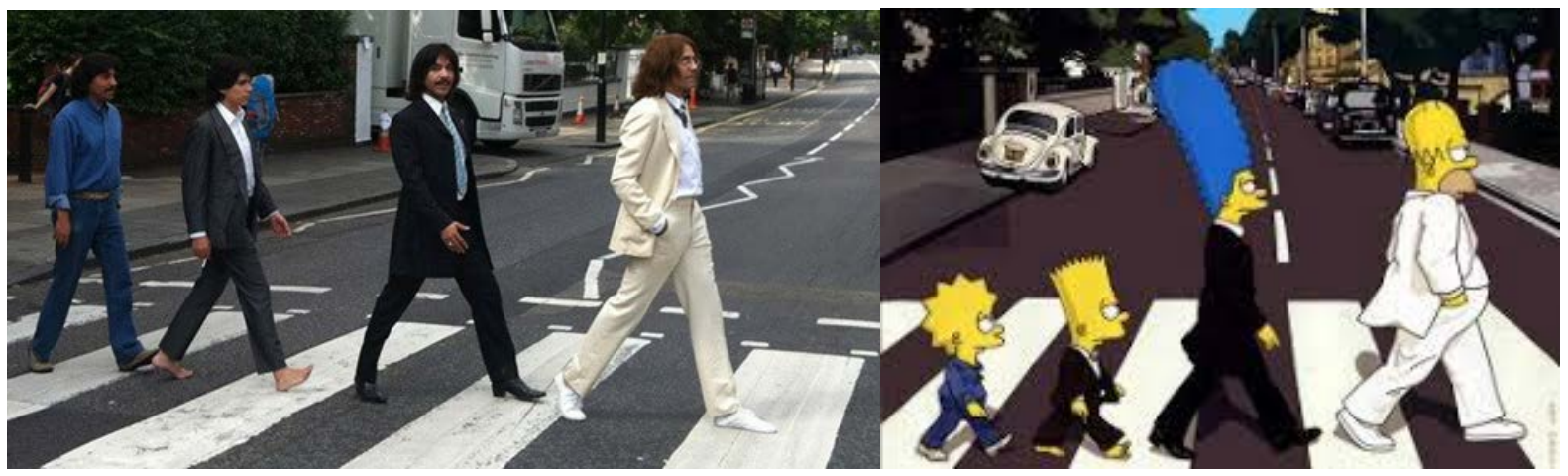

Fuentes: https://www.weplann.com/londres/tour-pop-rock; https://trucoslondres.com/abbey-road/

Cabinas rojas de teléfonos: En la actualidad las cabinas rojas de Londres son utilizadas principalmente para casos de emergencia, algunas están habilitadas como estación de carga para los dispositivos móviles y, por supuesto, para las fotografías de los turistas, ya que se han convertido en un icono turístico de su paso por Londres. La foto más emblemática se toma simulando una llamada de teléfono.

Figura 6. Cabinas rojas de teléfono (Londres)
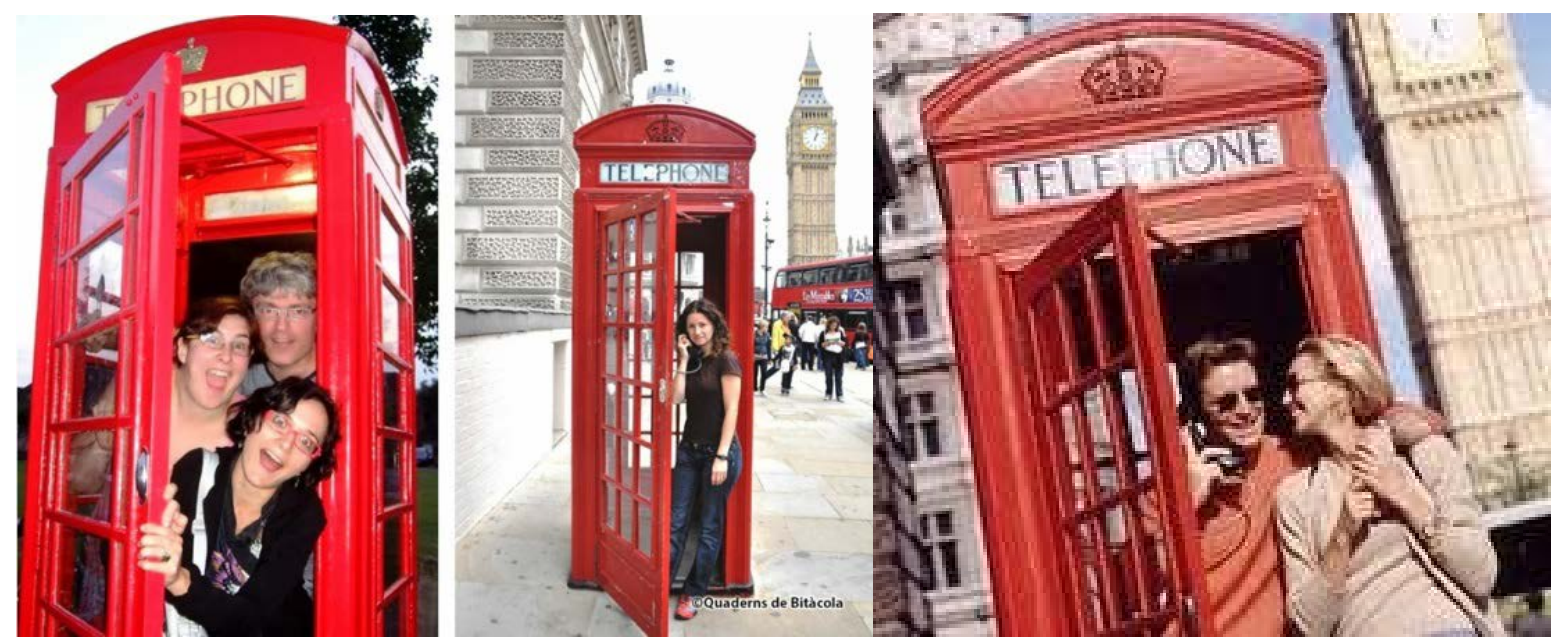

Fuentes:https://es.quadernsdebitacola.com/2013/10/typical-original-travel-photoscapitulo2.htm|\#.XH5xCYIKiUk; https://hemeroteca.vozlibre.com/noticias/ampliar/77687/ las-cabinas-rojas-de-londres-llegan-a-madrid

Grafiti del beso entre Honecker y Leónidas Breznev en el Muro de Berlín: Uno de los más famosos besos de la historia es el que tuvo lugar entre los líderes comunistas Erich Honecker, de Alemania Oriental, y Leónidas Breznev, de la Unión Soviética, durante el 30 Aniversario de la República Democrática Alemana en junio de 1979 (La caída del Muro de Berlín, s.f.). EI artista ruso Dimitri Vrúbel pintó en mural la famosa fotografía entre febrero y septiembre de 1990. Es una de las imágenes más emblemáticas de dicho Muro, convirtiéndose en uno de los 
puntos más visitados y fotografiados de la capital alemana. Los visitantes se fotografían imitando el gesto del beso delante del grafiti.

Figura 7. Grafiti del beso (Muro de Berlín)

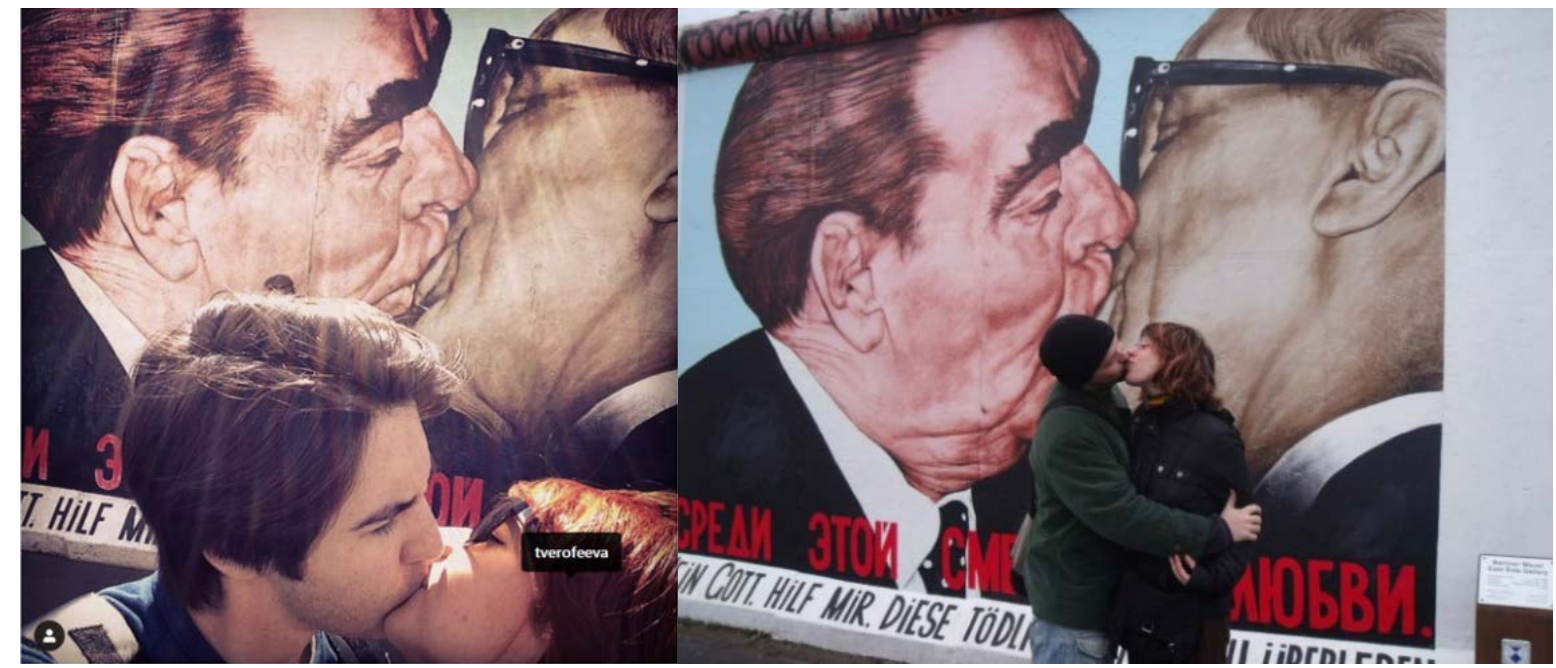

Fuentes:https://www.alamy.es/imagenes/berlin-wall-kiss-mural.html; https://locodelpelorojo. com/2009/10/16/muro-berlin-caida/

Como se observa en estas imágenes fotográficas emblemáticas de Europa tomadas como ejemplos, la acción de interacción con el icono es repetida por el turista o turistas protagonistas imitando al detalle la iconografía observada con anterioridad. Atendiendo a la acción y la simbología proyectada, la presencia del turista en la fotografía va má allá de su simple presencia. Existe una demostración activa de un comportamiento de interactuación con el icono turístico, dando prioridad a una acción simbólica específica, que, por supuesto, no es original. La intencianalidad final es proyectar un resultado similar a otras fotografías realizadas por otros turistas, denotando un claro consumo simbólico que refuerza la identidad del turista (Luna, 2015; Veblen 2010).

Algunos de estos iconos turísticos no son de valor patrimonial para la ciudad (por ejemplo el paso de cebra de Abbey Road o las cabinas rojas de teléfono de Londres), pero se hallan impregnados de un valor simbólico que los hace únicos y representativos de la ciudad. También se ha comprobado que, de algunos de estos iconos y su interacción con el mismo, se hacen otros tipos de referencias con proyección internacional a niveles que van más allá de la simple perspectiva turística, como son los dos casos expuestos: el paso de cebra de Abbey Road o la Boca della Veritá. Por lo tanto, y reforzando esta argumentación, tal y como exponen Stylianou-Lambert (2012), el turista se convierte en un productor cultural activo del destino a través de la creación y proyección de este tipo de fotografía turística, llegando a impregnar y/o reforzar de valor cultural del objeto fotografíado.

Siguiendo a Colás, González y De Pablos (2013), en la composición de la imagen es importante que se reconozca e identifique el destino a través de uno de sus principales iconos turísticos, marcando una interacción simbólica cuyo resultado es la demostración de 
su posesión (casos Torre de Pisa o la Torre Eiffel) y/o participación de un momento histórico (grafiti del beso en el Muro de Berlín o paso de cebra de Abbey Road).

Desde el paradigma del interaccionismo simbólico se puede analizar el papel del turista como protagonista de una escenografía dentro del espacio de ocio turístico (González Damián, 2010), siendo un sujeto activo en la edificación de la imagen de destino (Donaire y Galí, 2011). Los cuidados elementos simbólicos que se repiten en cada una de la fotografías tomadas son elementos de distinción de grupo, que lo serán para otros turistas que observen la imagen, siguiendo en la línea de Bourdieu (2003). En todas ellas se observa que la estética de la fotografía es de suma importancia, por lo que se cuidan detalles que es necesario repetir, o en todo caso mejorar, como la ubicación, posición, luz...,elementos cuyo alcance obliga a largas esperas, como si se tratase de la cola de un establecimiento. En ocasiones son interacciones relajadas y naturales (cruzar el paso de cebra de Abbey Road, llamar por teléfono en la cabina roja de Londres o besarse delante del Muro de Berlín), pero en otras son interacciones forzadas hasta lo imposible (coger la Torre Eiffel, la Torre de Pisa o la pirámide del museo de Louvre). Y no siempre aparece el turista en su totalidad, puede ser una parte del mismo, como la mano que sujeta la torre, mano que demuestra poseer una parte de la simbología o significación del icono.

En cuanto a la recreación escenográfica, en todas las imágenes la fotografía es tomada de frente o casi de frente, exceptuando el paso de cebra de Abbey Road que es tomada con la misma perspectiva en que fue tomada la imagen del disco de los Beatles, constituyendo una réplica exacta de la original. En cambio las fotografías de monumentos son tomadas desde cierta distancia y, a veces, altura, con la intención de jugar con la perspectiva y recreación de la interacción observada en otras fotografías similares. Desde la etnometodología de Garfinkel se podría afirmar que en todos los casos la repetición de la práctica de interacción, busca la construcción de la resignificación de una imagen simbólica en el mundo social.

Como se ha comprobado en esta fase de investigación, se han hallado algunas fotografías de interacción icónica de una denostada burla y mofa hacia el icono, especialmente en el caso de la Torre de Pisa tomado como elemento fálico. Estas imágenes de tono burlesco desvirtúan la imagen real del icono y, tal como asevera Gómez (2009), se hallarían en el lado opuesto al paradigma de la autenticidad. La teoría del conflicto permitiría analizar la transgresión del icono, sus intencionalidades y consecuencias interpretativas.

En cuanto a los resultados de la encuesta, se puede observar que la realización de fotografías durante el periodo de vacaciones es un comportamiento innato en sí mismo, un $87 \%$ responde que sí las realiza y un $12,3 \%$ a veces, no habiendo ni una sola persona que contestase que no realizaba fotografías. Consolidando en estos resultados una realidad incuestionable, y es que la fotografía conforma la pieza indispensable de toda experiencia turística (Luque et al., 2006 y Donaire y Galí, 2011, Hernández y Poggio, 2016), pues la imagen tomada será la que permita al turista evidenciar la demostración de la realización del viaje (Sontag, 2005). 
Tabla 2. Tabla cruzada: sexo y tipo de fotografía que realiza habitualmente el turista

\begin{tabular}{lcc|c|c|c|} 
& $\begin{array}{c}\text { De lo observado } \\
\text { sin presencia } \\
\text { del turista } \\
\text { protagonista }\end{array}$ & $\begin{array}{c}\text { De lo observado } \\
\text { con la presencia } \\
\text { del turista } \\
\text { protagonista }\end{array}$ & $\begin{array}{c}\text { Interactuando } \\
\text { con lo observado } \\
\text { por parte } \\
\text { del turista } \\
\text { protagonista }\end{array}$ & Indistintamente \\
\hline Hombre & $\%$ Dentro del sexo & $21,2 \%$ & $23,9 \%$ & $\mathbf{1 5 , 9 \%}$ & $38,9 \%$ \\
\hline Mujer & $\%$ Dentro del sexo & $17,2 \%$ & $20,1 \%$ & $\mathbf{1 6 , 0 \%}$ & $\mathbf{4 6 , 7 \%}$ \\
\hline
\end{tabular}

Fuente: elaboración propia

Sobre el tipo de fotografía que se realiza, la opción interactuando (tabla 2), se comprueba que tanto las mujeres (16\%) como los hombres $(15,9 \%)$ tienen valores muy próximos, aunque en la opción indistintamente, son las mujeres las que registran un valor más alto $(46,7 \%)$.

Tabla 3. Tabla cruzada: edad y tipo de fotografía que realiza habitualmente el turista

\begin{tabular}{|c|c|c|c|c|}
\hline$\%$ & $\begin{array}{c}\text { De lo observado sin } \\
\text { presencia del turista } \\
\text { protagonista }\end{array}$ & $\begin{array}{c}\text { De lo observado con } \\
\text { la presencia del turista } \\
\text { protagonista }\end{array}$ & $\begin{array}{l}\text { Interactuando con } \\
\text { lo observado por } \\
\text { parte del turista- } \\
\text { protagonista }\end{array}$ & Indistintamente \\
\hline Menos de 20 & $22,9 \%$ & $24,1 \%$ & $19,3 \%$ & $33,7 \%$ \\
\hline $20-29$ & $21,0 \%$ & $26,1 \%$ & $18,1 \%$ & $34,8 \%$ \\
\hline $30-39$ & $12,5 \%$ & $20,3 \%$ & $9,4 \%$ & $57,8 \%$ \\
\hline $40-49$ & $10,4 \%$ & $10,4 \%$ & $18,8 \%$ & $60,4 \%$ \\
\hline $50-59$ & $20,8 \%$ & $8,3 \%$ & $4,2 \%$ & $66,7 \%$ \\
\hline
\end{tabular}

Fuente: elaboración propia

En cuanto a los grupos de edad que suelen realizar más este tipo de fotografía de interacción (tabla 3), se observa que, frente al supuesto de partida (H.1), los intervalos de menos de 20 (19,3\%), de $20-29(18,1 \%)$ y el intervalo de $40-49(18,8 \%)$ son los que muestran un mayor porcentaje. No obstante, si se tiene en cuenta la opción indistintamente, podemos apreciar que son los intervalos de más edad los que tienen mayor porcentaje de realización (intervalo de $30-39$ con un $57,8 \%$, intervalo $40-49$ con un $60,4 \%$ e intervalo $50-59$ con un $66,7 \%)$. Por lo tanto, se puede afirmar que la hipótesis (H.1.) solo se cumple en parte, no solo los más jóvenes realizan este tipo de fotografía de interacción, por lo que se comprueba que existe una significación estadística, según la prueba de Pearson, aunque sea una correlación moderada (tabla 4).En este punto del análisis, y con respecto a este tipo de fotografía en particular, la distribución de las edades no muestra que sea solo el intervalo de los turistas jóvenes los que más la realizan, sino que abarca otros intervalos altos, contrariamente a lo que afirman en sus observaciones Ferrer y Bernal (2014) y Lo et al. (2011). En la revisión y localización de este tipo de fotografías en redes sociales e Internet se pudo observar que existía una amplia variedad en las edades de los turistas protagonistas. 
Tabla 4. Correlación entre edad y tipo de fotografía que realiza

\begin{tabular}{llr|r} 
& & Tipo de fotografía que realiza & \multicolumn{1}{c}{ Edad } \\
\hline Tipo de fotografía que realiza & Correlación de Pearson & 1 &, $201^{* *}$ \\
\cline { 2 - 4 } & Sig. (bilateral) &, 000 \\
\cline { 2 - 4 } & $\mathrm{N}$ & 357 & 357 \\
\hline \multirow{2}{*}{ Edad } & Correlación de Pearson &, $201^{* *}$ & 1 \\
\cline { 2 - 4 } & Sig. (bilateral) &, 000 & \\
\cline { 2 - 4 } & $\mathrm{N}$ & 357 & 357 \\
\hline
\end{tabular}

** La correlación es significativa en el nivel 0,01 (bilateral).

Fuente: elaboración propia

El tipo de fotografía de interacción icónica por sexo y edad, presenta la siguiente distribución (tablas 5 y 6), tanto hombres como mujeres realizan más el tipo de fotografía de interacción con monumentos-icono del destino visitado (tipo catedrales, edificaciones históricas, etc.) y las que menos, para ambos sexos, las esculturas-icono. En cuanto a la distribución por edades, se comprueba el mismo comportamiento, siendo los monumentos-icono los más recurrentes para la fotografía de interacción y las esculturas-icono las que menos. También se muestra (tabla 6) que el grupo de edad que más realiza este tipo concreto de fotografía es el intervalo entre $20-29$ con un 38,7\%. Los monumentos serían los iconos más emblemáticos y simbólicos para la interacción, más de apariencia social con aportación de prestigio, en la línea de la argumentación de Veblen (2010).

Tabla 5. Tabla cruzada: tipo de fotografía de interacción-icónica por sexo

\begin{tabular}{llc|c|} 
Tipo de interacción icónica & & Hombre & Mujer \\
\hline \multirow{4}{*}{ Total } & Esculturas-icono del destino visitado & $15,7 \%$ & $32,8 \%$ \\
\cline { 2 - 4 } & Monumentos-icono del destino visitado & $\mathbf{2 3 , 0 \%}$ & $\mathbf{5 2 , 4 \%}$ \\
\cline { 2 - 4 } & Otros objetos-icono del destino visitado & $20,4 \%$ & $39,5 \%$ \\
\hline
\end{tabular}

Fuente: elaboración propia

Tabla 6. Tabla cruzada: tipo de fotografía de interacción-icónica por edad

\begin{tabular}{lc|c|r|r|r|r} 
Tipo de interacción icónica & $<20$ & $\mathbf{2 0 - 2 9}$ & $30-39$ & \multicolumn{1}{|c|}{$\mathbf{4 0 - 4 9}$} & \multicolumn{1}{|c|}{$50-59$} & Total \\
\hline Esculturas-icono del destino visitado & $10,9 \%$ & $\mathbf{1 9 , 6 \%}$ & $9,8 \%$ & $5,9 \%$ & $2,2 \%$ & $48,5 \%$ \\
\hline Monumentos-icono del destino visitado & $17,1 \%$ & $\mathbf{2 7 , 7 \%}$ & $14,6 \%$ & $10,9 \%$ & $5,0 \%$ & $75,4 \%$ \\
\hline Otros objetos-icono del destino visitado & $14,0 \%$ & $\mathbf{2 4 , 6 \%}$ & $10,6 \%$ & $8,7 \%$ & $2,0 \%$ & $59,9 \%$ \\
\hline Total & $\mathbf{2 3 , 2 \%}$ & $\mathbf{3 8 , 7 \%}$ & $17,9 \%$ & $13,4 \%$ & $6,7 \%$ & $100,0 \%$ \\
\hline
\end{tabular}

Fuente: elaboración propia 
Sobre la relación de fotografías de interacción icónica presentadas en la encuesta, de las más habituales halladas en la revisión de Internet y redes sociales, los encuestados han ido marcando mayoritariamente las dos fotografías más típicas relacionadas con la interacción icónica: la cabina roja de teléfono en Londres $(40,89 \%)$ y la Torre de Pisa en Italia $(32,49 \%)$ (gráfico 1), siendo ésta la que más interacciones presenta con el turista (ver tabla 1), confirmando de esta forma la H3. Aunque los encuestados indican otros ejemplos de fotografías de interacción icónica, dentro y fuera de Europa, se toman como referencia solo aquellos que se hallan dentro de este continente.

Al relacionar los datos mostrados en el gráfico con el análisis de contenido, destaca la interacción icónica con la cabina roja de teléfono (Londres) por encima del resto de los iconos, desde el paradigma del interaccionismo simbólico el turista aparece como protagonista y sujeto activo a través de una interacción con el icono de forma más natural y cotidiana en el destino, acorde con lo argumentado por Donaire y Galí (2011). De todas las interacciones presentadas esta mencionada sería la más ordinaria, por lo tanto, la menos llamativa para el turista protagonista, pero cargada de gran simbología cultural, convirtiéndose el sujeto en productor cultural (Stylianou-Lambert, 2012).

\section{Gráfico 1. Relación de fotografías de interacción icónica en Europa}

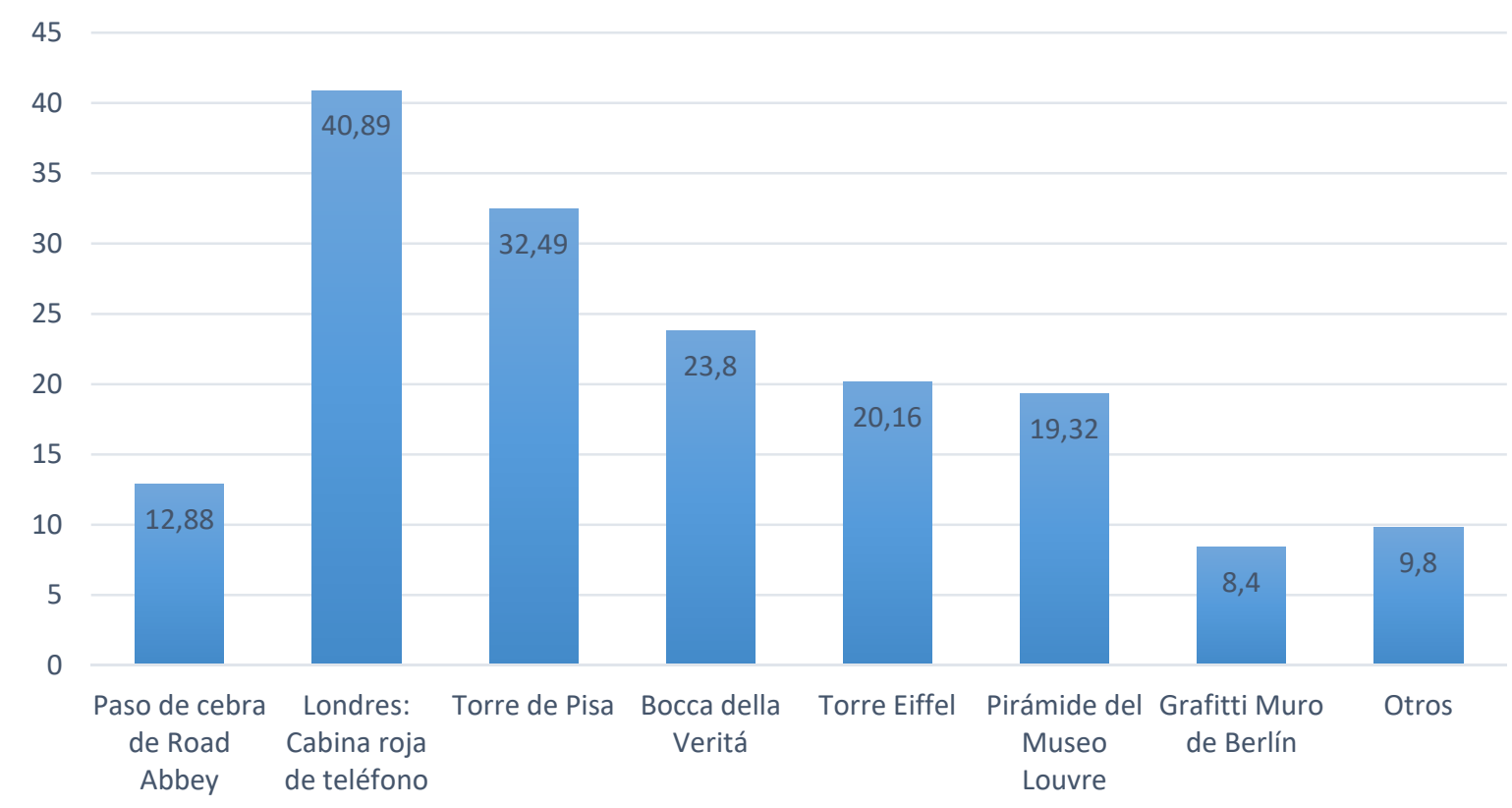

Fuente elaboración propia 
Gráfico 2. Motivo por el que realiza la fotografía de interacción

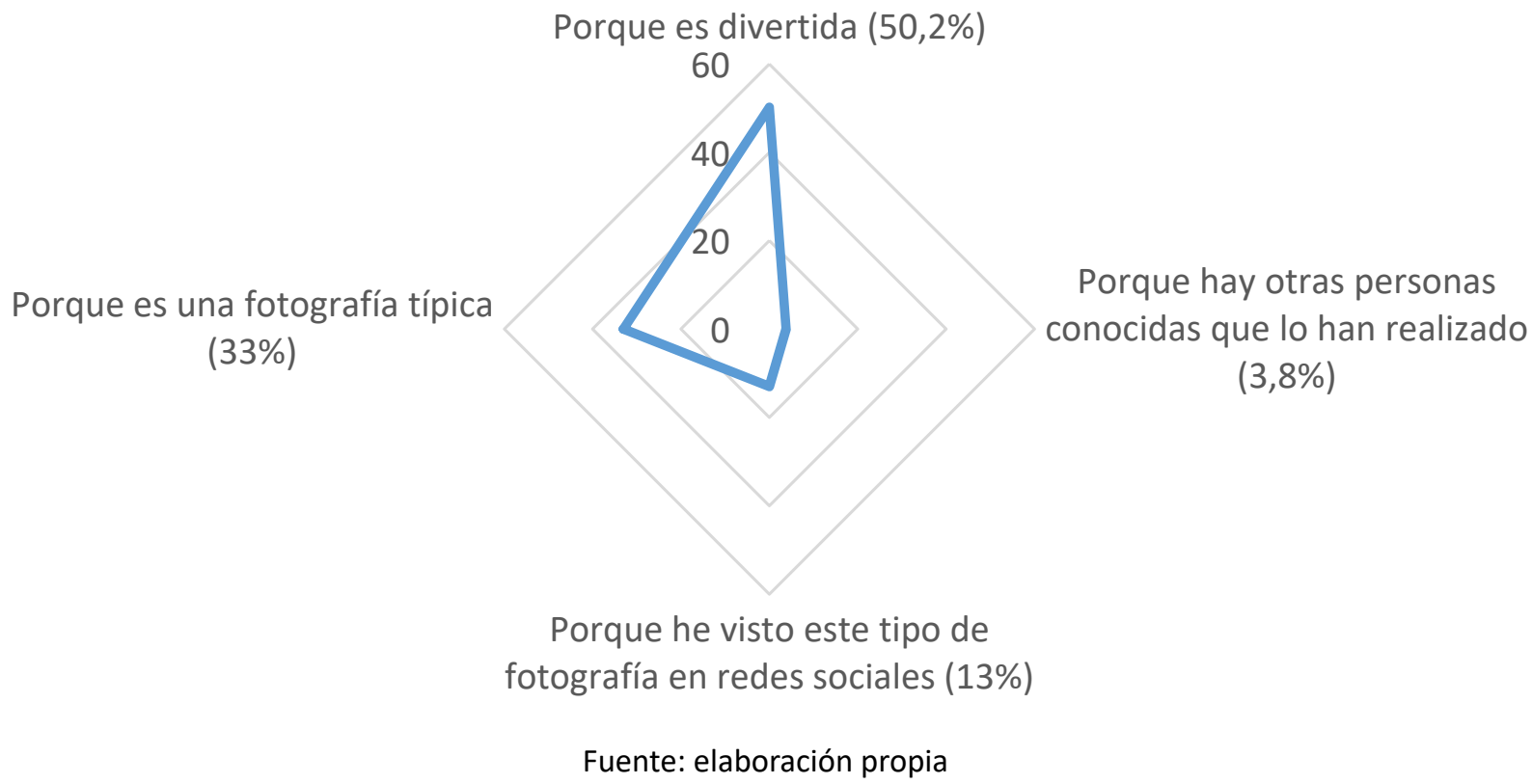

Entre los motivos que señalan para realizar este tipo de fotografía (gráfico 2) el 50,2\% lo hace porque lo considera divertido, seguido de un 33\% que lo realiza por ser una fotografía típica, observando que no se cumple nuestra hipótesis de partida (H.4) dado que se partía del supuesto de que el principal motivo era que se realizaba por ser una fotografía típica, siendo ésta la segunda motivación. No obstante, viniendo a reforzar lo que establecían Hart (2017) y Azevedo (2017), es de destacar que un 33\% indique que lo realiza porque en ellos ha despertado el deseo de copiar el comportamiento y la experiencia, además de contagiar emociones, motivo relacionado con la diversión que se destaca en primer lugar. Este comportamiento se puede relacionar con la idea del consumo simbólico, de narcisismo, búsqueda del hedonismo y exhibicionismo por parte del turista protagonista del que hablan Canavan (2017) y Gallego (2015). 
Gráfico 3. Tiempo que tarda en compartir la fotografía de interacción

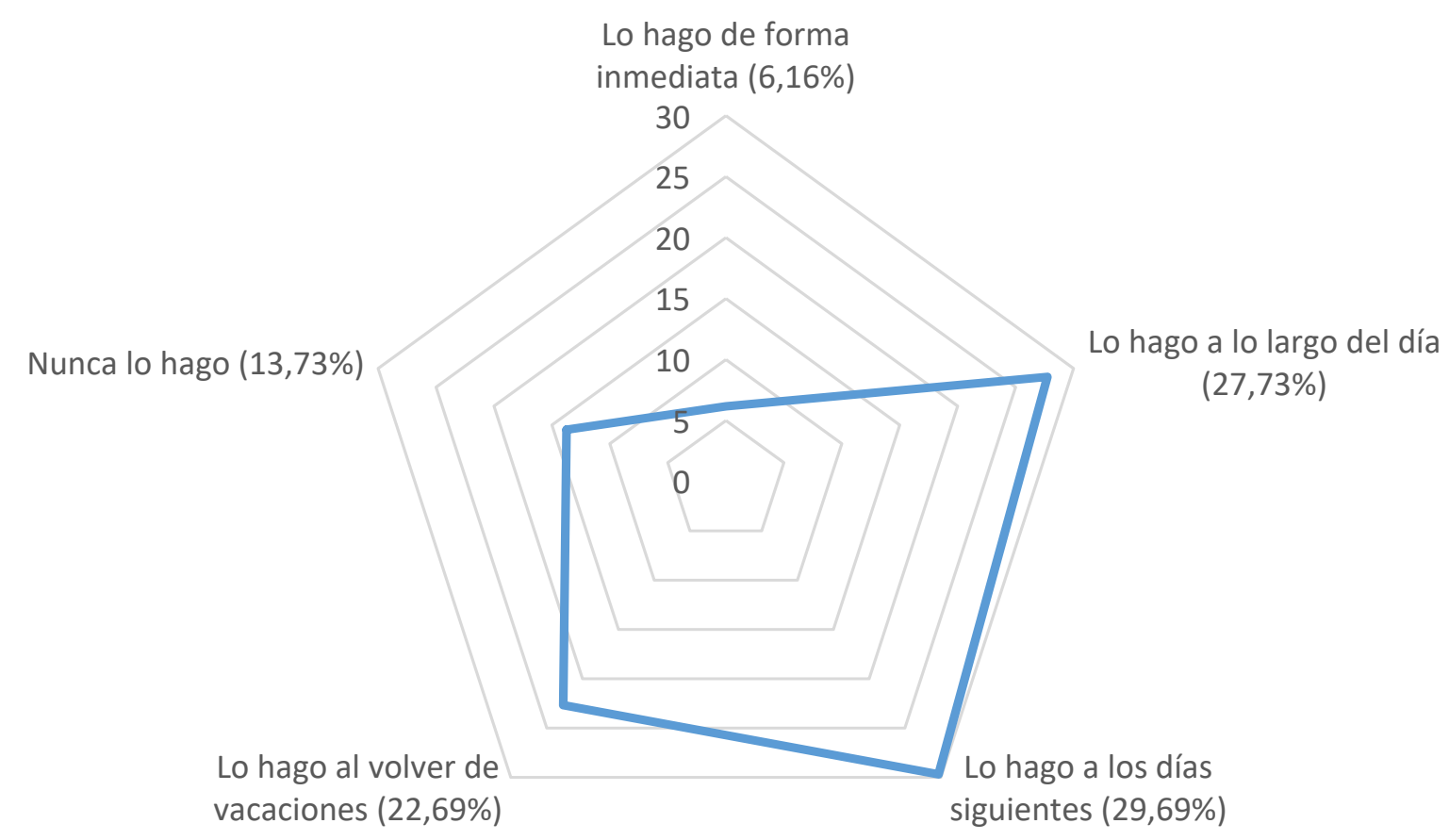

Fuente elaboración propia

Sobre el tiempo que tardan los turistas en compartir este tipo de fotografía (gráfico 3), los datos muestran que mayormente se realizan durante el periodo de vacaciones (tenemos un sumatorio de un $63,58 \%$, ) de los cuales el $27,73 \%$ lo hace a lo largo del día en que realiza la fotografía.

Tabla 7. Tabla cruzada edad y tiempo que tarda en compartir la fotografía

\begin{tabular}{lc|c|c|c|c|}
$\begin{array}{l}\text { Tiempo que tarda en } \\
\text { compartir }\end{array}$ & $\begin{array}{c}\text { Lo hago de forma } \\
\text { inmediata }\end{array}$ & $\begin{array}{c}\text { Lo hago a lo } \\
\text { largo del día }\end{array}$ & $\begin{array}{c}\text { Lo hago a los } \\
\text { días siguientes }\end{array}$ & $\begin{array}{c}\text { Lo hago al volver } \\
\text { de vacaciones }\end{array}$ & $\begin{array}{c}\text { Nunca lo } \\
\text { hago }\end{array}$ \\
\hline Menos de 20 & $31,8 \%$ & $15,2 \%$ & $31,1 \%$ & $24,7 \%$ & $16,3 \%$ \\
\hline $20-29$ & $13,6 \%$ & $48,5 \%$ & $39,6 \%$ & $43,2 \%$ & $20,4 \%$ \\
\hline $30-39$ & $31,8 \%$ & $20,2 \%$ & $11,3 \%$ & $13,6 \%$ & $28,6 \%$ \\
\hline $40-49$ & $13,6 \%$ & $11,1 \%$ & $10,4 \%$ & $11,1 \%$ & $28,6 \%$ \\
\hline $50-59$ & $9,1 \%$ & $5,1 \%$ & $7,5 \%$ & $7,4 \%$ & $6,1 \%$
\end{tabular}

Fuente: elaboración propia

En cuanto a la H2, los turistas-protagonistas más jóvenes son los que comparten habitualmente de forma más inmediata este tipo de fotografía, observamos que tanto el intervalo de menos de 20 años como los de 30 a 39 años, representan los porcentajes mayores de realización de forma inmediata, no cumpliéndose, en este sentido, la hipótesis de partida. Por lo tanto, el uso generalizado de compartir en redes sociales no es solo propio de los más jóvenes, extendiéndose su uso a otros rangos de edad, tal y como se argumentó con anterioridad, 
como demostración pública de compartir experiencias turísticas con cierto fingimiento iconográfico, tal y como apuntan Menezes y Gândara (2015). En este caso, los datos contradicen, en parte, lo indicado por Zheng y Gretzel (2010) y Gallego (2015) cuando afirman que son los más jóvenes los que comparten de forma inmediata, no obstante, si tenemos en cuenta el sumatorio $(63,68 \%)$ de todo el periodo vacacional, en realidad sí se comparte, aunque no de forma inmediata, antes del regreso del viaje.

En la pregunta sobre las plataformas a través de las cuales comparten estas fotografías (en la que se podía marcar más de una opción), se comprobó que el 52,7\% lo hace por WhatsApp, un 49,8\% por Instagram y un $28,5 \%$ por Facebook, en este orden de importancia, siendo Instagram la plataforma más utilizada por el intervalo de edad de menos de 20 años, confirmando de esta forma el estudio de Prades y Carbonell (2016).

Tabla 8. Motivo por el que comparte este tipo de fotografía según sexo

\begin{tabular}{|c|c|c|c|}
\hline Motivo de compartir este tipo de fotografía & Hombre & Mujer & Total \\
\hline Para informar a mi círculo de amigos/familia & $18,5 \%$ & $38,4 \%$ & $56,9 \%$ \\
\hline Para mostrar públicamente mi actividad turística & $12,4 \%$ & $25,1 \%$ & $37,6 \%$ \\
\hline Para reforzar mi imagen pública & $3,5 \%$ & $3,8 \%$ & $7,2 \%$ \\
\hline No me motivó hacerlo & $5,8 \%$ & $15,9 \%$ & $21,7 \%$ \\
\hline
\end{tabular}

Como se observa en la tabla 8 , los dos motivos principales por los cuales comparte este tipo de fotografía es para mantener informado a su círculo social $(56,9 \%)$ y para mostrar públicamente la actividad turística del turista $(37,6 \%)$, comprobando que se cumple la H.5 en su totalidad. Dichos datos reflejan la necesidad de mantener informado al entorno social sobre una experiencia vacacional cargada de simbología a través de este tipo de fotografía de interacción icónica.

\section{CONCLUSIONES}

Tras la investigación, el análisis sociológico de este tipo de fotografía permite comprender mejor la experiencia del ocio en el entorno urbano. Estas imágenes muestran la evidencia de que la intención principal del turista protagonista es repetir la acción simbólica, simulando una escenografía, como afirman Menezes y Gândara (2015); e indicar a su grupo de informantes que ha estado presente en ese lugar concreto, interactuando, de alguna forma, con un icono representativo del destino, compartiendo el reconocimiento de la imagen fotográfica (Gallego, 2015). Es por ello, que el paradigma del interaccionismo simbólico de Goffman será el que mejor explique esta interacción icono-turista, en el cual, turista e icono se relacionan, formando un conjunto de resignificación simbólica, tal y como afirma Raurich (2009).

Desde el enfoque de la teoría de Veblen (2010), se observa que la demostración de una narrativa vacacional es una proyección de una experiencia cargada de simbología, un proceso de demostración social del consumo de ocio turístico de ciertos iconos representativos, en definitiva, de consumo simbólico del que también hablan Sidun (2008) y Luna (2015). 
La interactuación generalizada con el icono representativo del lugar visitado viene dada por la necesidad del turista protagonista de mostrar una acción cargada de simbología que se impregna esencialmente de la misma, es como llevarse una pequeña parte del icono a través de la interacción con la misma y de su constatación fotográfica. Será a través de la misma cómo el turista-protagonista proyecta su imagen personal de destino, además de proyectar una demostración social (Sidun, 2008; Veblen, 2010). La interacción en sí, plasmada en la fotografía, lleva implícito el hecho de la apropiación del objeto icono, de la demostración de posesión (Colás, González y De Pablos, 2013), no es una simple fotografía al uso, es una fotografía cargada de valor consumista en el sentido que argumentan Bourdieu (2003) y Veblen (2010). Apropiarse del icono a través de la interacción, es como quien se lleva un suvenir personalizado, pero con mayor valor añadido, puesto que el turista protagonista forma parte del mismo.

La etnometodología será la que permita analizar cómo, a través de estos comportamientos reiterativos, el individuo construye una identidad social simbólica resignificada en el contexto vacacional. Comportamientos que son esencialmente importante compartir, dirán Colás, González y De Pablos (2013) para conseguir el reconocimiento ante los otros (Fuentes, 2014), de ahí también la necesidad de informar a los grupos de interés durante el transcurso de las vacaciones.

Por otro lado, se comprueba que no existen diferencias significativas en relación al sexo y la edad, en cuanto a la realización de la fotografía de interacción icónica y su predisposición a compartirla de forma inmediata por parte de los más jóvenes. En este punto del análisis, los datos no han secundado en su totalidad las argumentaciones de Zheng y Gretzel (2010), Lo et al. (2011), Ferrer y Bernal (2014) y Gallego (2015), aunque sí se ha podido comprobar que un porcentaje alto $(63,58 \%)$ comparte las fotografías realizadas durante su periodo vacacional. Por lo que, independientemente de estas variables (sexo y edad), existe una necesidad de protagonizar y compartir este tipo de fotografía de interacción icónica, por ser una fotografía divertida y típica, tal y como se reflejan en las principales motivaciones expuestas por los turistas, en definitiva, el turista refleja una imagen personal simbólica de destino dirigida a su entorno social cercano.

La interacción de divertimento reflejada en la fotografía, la repetición de imágenes observadas y la necesidad de informar sobre el viaje contienen, de forma tácita, el discurso del narcisismo, del exhibicionismo ante el grupo social del que hablan Canavan (2017) y Gallego (2015). Comunicar al grupo social próximo sobre la parte emocional y de refuerzo de imagen personal en el destino se convierte en imprescindible, además de alimentar el ego del turista protagonista.

En ocasiones, el tipo de interacción icónica realizada y observada en el análisis de contenido de las fotografías objeto de estudio, muestran una escena simbólica inverosímil, pero que de algún modo resultan reales para los individuos que las visualizan. Aun siendo conscientes de la falsa realidad, ésta continúa ejerciendo el suficiente atractivo como para alimentar la necesidad de imitar la escenografía observada. 
Esta propuesta conceptual y el análisis que se aplica sobre este tipo de «fotografía de interacción icónica» se construyen con el objeto de presentar una explicación plausible a un comportamiento simbólico vacacional que se viene dando en los últimos tiempos, comportamiento con una relevante presencia en redes sociales y otro tipo de plataformas tecnológicas. La contribución académica del artículo es significativa desde la perspectiva sociológica, por el hecho de ser una propuesta conceptual y de análisis novedosa en sí misma, además de apuntalar la necesidad de continuar con más investigación y análisis que aporte mayor comprensión sobre este comportamiento turístico, que a la postre, parece buscar el refuerzo simbólico de la imagen personal en el destino.

Finalmente, la presente investigación puede mostrar ciertas limitaciones derivadas del tamaño de la muestra, por lo que sería interesante ampliar la misma para disminuir el error muestral. Por otra parte, abre la posibilidad de una nueva línea de investigación sobre este fenómeno social en otros contextos geográficos, pues se ha encontrado gran cantidad de casos de fotografía de interacción icónica en otros continentes. Asímismo, se podría ampliar el análisis desde otros niveles disciplinarios, además del sociológico.

\section{BIBLIOGRAFÍA}

Álvarez Sousa, A. (2009) Sociología del turismo. Udima, Centro de Estudios Financieros. Madrid: Ediciones CEF

Azevedo, A. (2017) Significados latentes na fotografía em turismo: o caso do turismo negro na Costa Morte (Galiza). Revista Pasos, 15 (4), 1001-1015. Recuperado de: http://www. pasosonline.org/Publicados/15417/PS417 16.pdf

Baltar, F. y Gorjup, T. (2012) Muestreo mixto online: una aplicación en poblaciones ocultas. Revista Intangible Capital, 8 (1), 123-149.DOI: http://dx.doi.org/10.3926/ic.294

Barthes, R. (1989) La cámara lúcida. Nota sobre la fotografía. Barcelona: Editorial Paidós.

Barrios, J. L. (2010) Atrocitas fascinans: imagen horror, deseo. México: Editorial Rastro Blanco.

Bericat Alastuey, E. (2012) Ciencias sociales y cultura audiovisual: el conocimiento de la fotografía, en J.A. Roche Cárcel (Ed.) La sociología como una de las bellas artes. Barcelona: Anthropos, 201-224. Recuperado de: https://www.researchgate.net/ publication/296695431 Ciencias sociales y cultura audiovisual el conocimiento de la fotografia

Brickman-Bhutta, C. (2012) Not by the book: Facebook as sampling frame. Sociological Methods \& Research, 41 (1), 57-88. DOI: https://doi.org/10.1177/0049124112440795

Bourdieu (2003) Un arte medio. Ensayo sobre los usos sociales de la fotografía. Barcelona: Editorial Gustavo Gili.

Canavan, B. (2017) Narcissism normalisation: Tourism influences and sustainability implications. Journal of Sustainable Tourism, 25(9), 1322-1337. https://doi.org/10.1080/0966 9582.2016.1263309

Caro, J. L., Luque, A., \& Zayas, B. (2015) Nuevas tecnologías para la interpretación y promoción de los recursos turísticos culturales. Revista Pasos, 13 (4), 931-945. Recuperado de:http://www.pasosonline.org/es/articulos/817nuevas tecnologas para la interpretacin $y$ promocin de los recursos tursticos culturales 
Colás P., González, T. y De Pablos, J. (2013) Juventud y redes sociales: motivaciones y usos preferentes. Revista Comunicar, Vol. XX (40), 15-23. DOI: https://doi.org/10.3916/ C40-2013-02-01

Daries-Román, N., Cristóbal-Fransi, E. y Martín-Fuentes, E. (2014) Promoción turística de las Comunidades Autónomas españolas a través de las redes sociales. Revista Papers de Turisme, no 55, 84-106. Recuperado de: http://www.papersdeturisme.gva.es/ojs/ index.php/Papers/article/view/187/157

Donaire J.A. y Galí, N. (2011) La imagen turística de Barcelona en la comunidad Flickr. Cuadernos de Turismo, no 27, 291-303

El Confidencial (31/03/2019) 130 años de la Torre Eiffel: Historia del icono que ha vivido más de un siglo de prestado. Recuperado de https://www.elconfidencial.com/ cultura/2019-03-31/130-anos-torre-eiffel 1894458/

Ferré Pavía, C., y Bernal, A. (2014) Jóvenes e Internet: protagonismo y dudas. En El uso de las redes sociales: ciudadanía, política y comunicación (31-32), Barcelona: E-Book Instituto de Comunicación UAB. Recuperado de: https://ddd.uab.cat > pub > llibres > 2014 > Ebook_INCOM-UAB_6

Fuentes, C. (2014) Foto-turismo: la constitución social de una mirada persistente. Revista Valenciana, 7 (13), 7-29. Recuperado de: http://www.scielo.org.mx/scielo. php?script=sci arttext\&pid=S2007-25382014000100001\&lng=es\&tlng=es.

García del Toro, J.J. (2016) Evolución de la imagen turística a través de la fotografía histórica. Revista Canaria de Patrimonio Documental no 12, 205-218. Recuperado de: https:// dialnet.unirioja.es/servlet/articulo?codigo $=5915998$

Gallego Dueñas, Francisco Javier (2015) Propuesta para una sociología de la fotografía turística. Revista Imagonautas, Revista interdisciplinaria sobre imaginarios sociales, $\mathrm{n}$ 은 5 especial sobre «imaginarios urbanos» (1-2), 46-65. Recuperado de: https://www. academia.edu/15728291/Propuesta_para_una_sociolog\%C3\%ADa de la fotograf\%C3\%ADa tur\%C3\%ADstica

Garrod, B. (2009) Understanding the relationship between tourism destination imagery and tourist photography. Journal of Travel Research, 47(3), 346-358. https://doi. org/10.1177/0047287508322785

Guash, A. M. (2013) Os lugares da memoria: a arte de arquivar e recordar. Revista Valise 03 (05), 237-264.Recuperado de: http://revistes.ub.edu/index.php/materia/article/ view/11382

Goffman, Erving (1971) Ritual de la interacción. Buenos Aires: Editorial Tiempo Contemporáneo.

González Damián, A. (2010) El Turismo en la sociología contemporánea, una aproximación. Anuario Turismo y Sociedad, Vol. XI, Universidad Externado de Colombia, 119142. Recuperado de: https://revistas.uexternado.edu.co/index.php/tursoc/article/ view/2831

González García, L.M.; Sosa Hernández, J.J. y Fierro Martínez, S. (2018) Muestreo online basado en redes sociales para la localización de teletrabajadores como participantes de un estudio realizado en Victoria de Durango, México. Paakat, Revista de Tecnología y Sociedad, año 8 (15). DOI: http://dx.doi.org/10.32870/PK.a8n15.333 
González Fernández-Villavicencio, N. (2012) Alfabetización para una cultura social, digital, mediática y en red. Revista Española de documentación científica, no Monográfico, 17-45 DOI: https://doi.10.3989/redc.2012.mono.976

Gómez Lozano, D. (2009) El fotógrafo y la ciudad. Del estereotipo a la banalidad. Revista do Centro de Educaçâo a Distancia-EAD/UDESC. 2 (2), 2-8. Recuperado de: http://www. revistas.udesc.br/index.php/udescvirtual/article/view/1969

Gunter, Joel (2017) Diario digital El Mundo: https://www.bbc.com/mundo/noticias-38705447

Hart Robertson, Margarita (2016) Para no perder el norte: fotografía, identidad y memoria en Gran Canaria como destino turístico integral. Revista Canaria de Patrimonio Documental, no 12, 87-94. Recuperado de: https://dialnet.unirioja.es/descarga/articulo/5915993.pdf

Heckathorn, D.D. (1997) Respondent-driven sampling: a new approach to the study of hidden populations. Social Problems, 44 (2), 174-199. DOI: https://doi.org/10.2307/3096941

Heckathorn, D.D. (2002) Respondent-driven sampling II: deriving valid population estimates from chain-referral samples of hidden populations. Social Problems, 49 (1), 11-34. DOI: https://doi.org/10.1525/sp.2002.49.1.11

Hernández Correa, V. y Poggio Capote, M. (2016) Albores turísticas en la Palma: viajeros y fotografía en la Isla Bonita (1900-1960). Revista Canaria de Patrimonio Documental, no 12, 155-204. Recuperado de: https://dialnet.unirioja.es/servlet/articulo?codigo=5915997

Hiernaux, D. (2012) Turismo e imaginarios. In: Hiernaux, Cordeiro e Montijn. Imaginarios sociales y turismo sostenible. Facultad Latino Americana de Ciencias Sociales. Costa Rica, 7-35.

Instituto Gallego de Estadística (IGE). Recuperado de https://www.ige.eu/igebdt/ esqv.jsp?c $=0201001002 \&$ ruta $=$ verPpalesResultados.jsp? $O P=1 \& B=1 \& M=\& C O D=$ 589\&R=9913[all] \&C=T[1:0];0[all]\&F=\&S=

Jafari, J. (2007) «Modelos del turismo: los aspectos socioculturales». In: Lagunas, D. (Coord.)

Antropología y Turismo. Claves Culturales y Disciplinares, pp. 47-71. México: Editorial Plaza y Valdés.

La caída del Muro de Berlín (s.f.) Recuperado de: La historia de un beso https://sites.google. com/site/631lacaidadelmurodeberlin/la-historia-de-un-beso/la-historia-de-un-beso

Lara T. (2011) Alfabetizar en la cultura digital. Blog Tiscar.com. Recuperado de: https://es.slideshare.net/tiscar/alfabetizar-en-la-cultura-digital-2008

Lo, I. S., McKercher, B., Lo, A., Cheung, C., \& Law, R. (2011). Tourism and online photography. Tourism management, 32(4), 725-731. DOI: 10.1016/j.tourman.2010.06.001

López de letona y Roldán, J. A. (s.f.) Individuo, masa, ocio, cultura y libertad. Apuntes para una sociología del turismo. Revista Estudios, 41-48. Recuperado de: https://dialnet. unirioja.es/servlet/articulo?codigo $=2208333$

Lúque, P; López, L.; Blanchard, R. y Sánchez, M. (2006) La fotografía: una experiencia para el aprendizaje de la práctica turística y la promoción del turismo en el Zulia. Revista de Artes y Humanidades UNICA, Vol. 7 no 6, 189-205. Venezuela. Recuperado de: www. redalyc.org/pdf/1701/170118726010.pdf

Luna Cortés, G. (2015) Una revisión del constructo consumo simbólico desde la perspectiva de la experiencia turística. Revista Investigaciones Turísticas, no 10, julio-diciembre, 26-56. DOI: https://doi.org/10.14198/INTURI2015.10.02 
Machado, A. (2010) La fotografía como expresión de concepto. Biblioteca Virtual Miguel de Cervantes, 100-110. Recuperado de: http://www.cervantesvirtual.com/nd/ark:/59851/ bmcqr588

Manosso F.C. y Gândara J.M. (2016) La materialización de la experiencia en el espacio urbano-turístico a través de las fotografías online. Revista Estudios y Perspectivas en Turismo, Vol. 25, 279-303. Recuperado a partir de: http://www.redalyc.org/articulo. oa?id=180746305003

Menezes Mello, C. y Gândara, J.M. (2015) Los discursos fotográficos de los viajeros. CuritibaBrasil en Tripadvisor. Revista Estudios y Perspectivas en Turismo. Brasil: Universidad Federal do Panamá, Curitiba, 627-645. Recuperado a partir de: https://dialnet.unirioja. es/servlet/articulo?codigo $=5276643$

News. Mundo (2017) Yolocausto ¿está bien tomarse fotos en los monumentos que recuerdan a las víctimas del Holocausto? Recuperado de https://www.bbc.com/mundo/ noticias-38705447

París CityVision Recuperado de: https://www.pariscityvision.com/es/paris/museos/ museo-louvre/piramide-louvre-historia-arquitectura-leyendas

Pérez Gallardo, H. (2015) Fotografía y arquitectura en el siglo XIX: historia y representación monumental. Madrid: Editorial Cátedra.

Prades, M y Carbonell, X (2016) Motivaciones sociales y psicológicas para usar Instagram. Revista Comunication Papers, 5 (9), 27-36. Recuperado de: https://dialnet.unirioja.es/ servlet/articulo?codigo $=5904732$

Ramos Soler, I, Del Pino Romero, C. y Castelló Martínez. A. (2014) La Investigación en redes sociales y web 2.0. Estudio bibliométrico. Capítulo IX en Durán Medina (coord.) Comunicación 2.0 y 3.0., 191-209. Madrid: Editorial Visión Libros.

Raurich Valencia, V. (2009) Lugares comunes: fotografía y turismo. Ankulegi no 13, 33-43. Recuperado a partir de: https://dialnet.unirioja.es/descarga/articulo/3290798.pdf

Reig, D. y Vilches, L. (2013) Los jóvenes en la era de la hiperconectividad: tendencias, claves y miradas. Madrid: Fundación Telefónica.

Sidun, Ayelen (2008) Fotografía turística: la visión después de la mirada. Revista Oficios Terrestres no 21, 106-109. Recuperado de: http://hdl.handle.net/10915/45561

Silenzio, V.M.; Duberstein, P.R.: Tang, W.; Lu, N.: Tu, X. \& Homan, C.M. (2009) Connecting the invisible dots: Reaching lesbian, gay, and bisexual adolescents and young adults at risk for suicide through online social networks. Social Science and Medicine, 69 (3), 469474. DOI: https://doi.org/10.1016/i.socscimed.2009.05.029

Sheungting Lo, Iris \& McKercher, Bob (2015) Ideal image in process: online tourist photography and impression management. Annals of tourism Research, vol. 52, 104-116 DOI: https://doi.org/10.1016/j.annals.2015.02.019

Sontag, Susan (2005) La fotografía. Madrid: Editorial Alfaguara.

Sontag, Susan (2010) Sobre la fotografía. Barcelona: Debolsillo.

Stepchenkova, S., \& Zhan, F. (2012) Visual destination images of Peru: Comparative content analysis of DMO and user-generated photography. Tourism Management, 36, 590-601. Doi: http://dx.doi.org/10.1016/i.tourman.2012.08.006

Stylianou-Lambert, T. (2012) Tourists with Cameras: Reproducing or Producing. Annals of Tourism Research, 39(4), 1817-1838. DOI: http://dx.doi.org/10.1016/i.annals.2012.05.004 
Van Dijck, J. (2008) Digital photography: Communication, identity, memory. Visual Communication, 7(1), 57-76. DOI: https://doi.org/10.1177/1470357207084865

Van House, N.A. (2011) Personal photography, digital technologies, and the uses of the visual. Visual Studies, 26(2), 125-134. DOI: http://10.1080/1472586X.2011.571888

Veblen, T. (2010) Teoría de la clase ociosa. Edición original 1899. Fondo Cultura Económica.

Vega, C. (2011) Lógicas turísticas de la fotografía. Madrid. Cátedra.

Verd Pericás, J.M. y Martí Olivé (1999) Muestreo y recogida de datos en el análisis de redes sociales (1999). Qüesttió, vol. 13 (3), 507-524. Recuperado de: https://dialnet.unirioja. es/servlet/articulo?codigo $=2946780$

Zheng, X \& Gretzel, U. (2010) Role of social media in online travel information searh. Tourism Management, 31, 179-188. DOI: http://dx.doi.org/10.1016/i.tourman.2009.02.016 